\title{
Filosofia e imaginação: uma discussão sobre a hermenêutica de Friedrich Schleiermacher
}

Philosophy and imagination: discussion on Friedrich Schleiermacher's hermeneutics

Aloisio Ruedell *

recebido: $10 / 2012$

aprovado: 01/2013

\begin{abstract}
Resumo.
A questão da imaginação sempre esteve presente na história da filosofia. E a faculdade da imaginação identifica-se, de certa forma, com a faculdade de pensar. Isso ainda fica mais claro na perspectiva da hermenêtica, para a qual a linguagem não é transparente, porque sempre situada em circunstâncias históricas concretas. Sua compreensão requer interpretação e certo exercício de imaginação, em direção às circunstâncias particulares que a constituem. O propósito deste artigo é examinar brevemente a questão da imaginação na hermenêutica de Friedrich Schleiermacher, de modo a evidenciar a importância dessa questão na filosofia e em toda produção do conhecimento.

Palavras-chaves: linguagem, imaginação, divinação, interpretação psicológica, interpretação gramatical.
\end{abstract}

Abstract:

The question of imagination has always been present in the history of philosophy. And the faculty of imagination identifies himself, in a way, with the faculty of thinking. This also becomes clear from the perspective of hermeneutics, for which the language is not transparent, because always situated in concrete historical circumstances. Their understanding and interpretation requires some exercise of imagination towards the particular circumstances that constitute it. The purpose of this article is to briefly examine the question of imagination hermeneutics of Friedrich Schleiermacher, in order to highlight the importance of this question in philosophy and all knowledge production.

Keywords: language, imagination, divination, psychological interpretation, grammatical interpretation.

Doutor em Filosofia pela PUCRS. Professor de Filosofia no Departamento de Humanidades e Educação (DHE) da UNIJUI, em Ijui e Santa Rosa/RS. 
A faculdade da imaginação está, sem dúvida, pressuposta em toda discussão filosófica. Identifica-se, de certa forma, com a faculdade de pensar. Adquire, porém, importância especial na perspectiva da hermenêutica, para a qual a linguagem não é transparente, porque sempre situada em circunstâncias históricas concretas. Sua compreensão requer interpretação e certo exercício de imaginação, em direção às circunstâncias particulares que a constituem. O propósito deste ensaio é examinar brevemente a questão da imaginação na hermenêutica de Friedrich Schleiermacher, de modo a evidenciar a importância dessa questão na filosofia e em toda produção do conhecimento.

A investigação desse tema não significa que o autor tenha algum texto no qual trate especificamente da questão da imaginação. Esta, porém, perpassa todo o seu projeto hermenêutico. Este seria impensável, se não contasse já sempre com a faculdade da imaginação. Vale-se dela o autor e o leitor ou intérprete. Sem fazer um exame exaustivo de todo o projeto hermenêutico, escolhi apenas alguns aspectos ou elementos em vista da questão aqui colocada.

\section{As condições da compreensão do discurso}

Schleiermacher concebe a hermenêutica a partir de duas condições básicas, a consciência livre e criadora do sujeito e a linguagem. São condições da compreensão e da interpretação porque também já estão na base do discurso que estabelece o sentido. "Todo discurso - afirma ele - tem uma dupla relação, para o todo da linguagem e para o todo do pensamento do autor" (2005, p. 95). O discurso é, por assim dizer, a encruzilhada da compreensão: nele se constitui e compreende a 
linguagem, e é também nele que se compreende a estrutura interna do ser humano. Sua compreensão dá-se sob estes dois aspectos, como "extraído da linguagem" e como "fato naquele que pensa", que profere ou escreve o discurso. É uma compreensão sob dois pontos de vista, assumidos, respectivamente, na interpretação gramatical e na interpretação psicológica. Como autor e linguagem são inseparáveis na constituição de uma obra ou discurso, também essas duas perspectivas de interpretação e compreensão exigem-se mutuamente, e são igualmente importantes (Schleiermacher, 1990, p. 79). ${ }^{1}$ Não é possível compreender um discurso enquanto fato do espírito, sem compreendê-lo também enquanto designação de uma língua. Da mesma forma, um discurso só é compreendido como "extraído da linguagem" na medida em que também for compreendido enquanto "fato do espírito", que influi na própria constituição de uma língua (Schleiermacher, 1990, p. 79).

Trata-se, portanto de dois aspectos ou perspectivas de uma mesma compreensão. Isso, porém, não impede a Schleiermacher de abordá-los separadamente, na interpretação gramatical e na psicológica.

\subsection{A interpretação gramatical}

A compreensão de um texto, de qualquer gênero que seja, requer que se saiba o sentido dos termos nele usados, ou seja, que se conheça a linguagem da qual dispunha o autor. É isso que se propõe na interpretação gramatical, visando à compreensão do discurso, enquanto articulação da estrutura de uma língua.

Duas regras básicas ou cânones orientam essa perspectiva de interpretação. Numa o discurso é visto em seu todo, enquanto determinação paradigmática, ou seja, enquanto determinado 
pelo "âmbito da linguagem comum ao autor e seu público originário" (Schleiermacher, 1974, p. 86 e 1990, p. 101). ${ }^{2}$ É o discurso enquanto manifestação da gramática, mas uma gramática historicamente dada, que conserva "a interpretação coletiva e prática, que, em dada época, determinado grupo ou sociedade fez referente à relação entre os seus membros e ao mundo que lhes é comum" (Frank, 1985, 290). A título de ilustração, pode-se referir o exemplo que Schleiermacher deixa em Das Leben Jesu (= A Vida de Jesus), demonstrando que ninguém pode ser arrancado de sua época e de seu povo. "Cristo - afirma ele - não se podia expressar de outra maneira, a não ser através da linguagem que lhe era familiar e que estava na base de sua vida social com as outras pessoas" (1864, p. 13). Ou seja, inserido num povo e vivendo em determinada época, Ele só podia influenciar os outros e deixar sua mensagem, valendo-se de representações vigentes.

A segunda regra da interpretação gramatical considera o discurso em suas relações lineares ou como determinação sintagmática: "O sentido de um termo numa determinada passagem precisa ser definido segundo suas relações com os que o precedem e sucedem" (Schleiermacher, 1990, p. 116). É a consideração do discurso enquanto resultado da imaginação e de um ordenamento criativo de seu autor. Diz respeito ao discurso enquanto fator de transformação e de inovação. Isso mais uma vez pode ser verificado exemplarmente nos discursos de Jesus, em Das Leben Jesu. Se a língua materna foi para Ele uma conditio sine qua non para a formulação de sua mensagem, isso ainda não quer dizer que também tenha sido sua ratio per quam. Se tivesse sido assim, argumenta o filósofo, "Cristo nem teria sido necessário, e o conhecimento de Deus se teria difundido por si através da linguagem" (Schleiermacher, 1864, p. 13). Isso, obviamente não foi o caso. É impensável que uma língua se transforme e desenvolva sem a atuação de alguém, e sem esse desenvolvimento, a rigor, não pode haver novidade. Assim, 
Jesus, para que pudesse ser significativo e deixar uma mensagem nova, não apenas se serviu da linguagem da época, mas sua mensagem também foi uma verdadeira investida contra ela, de modo a provocar a "transformação semântica de sua visão de mundo" (Frank, 1985, p. 291).

Vinculada a esses dois cânones fundamentais, "há mais uma série de pares de oposição (formal-material; qualitativoquantitativo; mecânico-orgânico) que, juntamente com os primeiros, instituem uma diversidade de combinações e de pontos de vista possíveis da interpretação gramatical" (Frank, 1985, p. 266-267). Aqui, porém, não há necessidade de uma análise detalhada de todas essas possibilidades. O importante é destacar que todas elas têm em comum o princípio de que "nenhum elemento isolado pode ser compreendido por si" (Frank, 1985, p. 267), desvinculado de sua função ou lugar que ocupa no todo que integra. Tudo ainda "necessita de uma definição mais acurada, e a obtém na relação. Cada parte do discurso, tanto material quanto formal, é em si indeterminada" (Schleiermacher, 1974, p. 86). E é precisamente aí, na indeterminação, que entra a imaginação. Ela entra em ação, em busca de uma definição ou determinação, possível e provisória, daquilo que no discurso ou no texto ainda está indefinido ou não dito.

\subsection{Interpretação psicológica e/ou técnica}

A compreensão do sentido de um texto conduz necessariamente àquilo que Schleiermacher designa por interpretação técnica, destacando-a do contexto mais amplo da interpretação psicológica. Nem sempre ele faz essa diferenciação terminológica. O emprego deste último termo tem, por vezes, um sentido bem amplo, referindo-se, ao mesmo 
tempo, ao autor e a seu estilo. Mas há também, de outro lado, um uso mais restrito de cada termo, ao menos a partir de 1832 (Frank, 1985, 314), referindo-se com um ao aspecto propriamente psicológico do autor e, com outro, ao estilo.

Há, sem dúvida, em Schleiermacher, um vínculo muito estreito entre estilo ou tendência do texto e seu autor. Um remete a outro. É no estilo que se revela o autor, e aquele, por sua vez, só se elucida à luz deste, conhecendo sua intenção. Isso, contudo, não quer dizer que seja fácil saber a intenção do autor. Ao contrário, afirma o filósofo, há obras que são verdadeiros "enigmas hermenêuticos" (Scholtz, 1995, p. 114). No mais, o desafio de saber a intenção do autor e de conhecer a tendência ou o estilo da obra ainda não esgota a tarefa da interpretação. Pois, o que se pretende é compreender o autor "não apenas tão bem quanto ele mesmo se compreendia, mas ainda melhor" (Schleiermacher, 1974, p. 108 e Scholtz, 1995, p. 114). Considerar, por exemplo, o contexto histórico e a influência posterior de sua obra sobre a linguagem é um ideal de conhecimento inacessível ao autor.

Quando se fala de uma interpretação especificamente psicológica, inclui-se como objeto de interpretação a vida do autor, no sentido de saber os "motivos" que o levaram a escrever. Para não subestimar a essa perspectiva de interpretação, importa prestar bem atenção ao que Schleiermacher realmente quer dizer. Ao perguntar pelos "motivos" e pelo "projeto originário" de uma obra, pergunta-se, em verdade, pelas circunstâncias que a provocaram. O autor não é uma figura abstrata, mas situado num contexto, que, de alguma forma, o constitui. E certamente não é sempre indiferente ter diante de si apenas uma obra a ser interpretada ou ter, além disso, uma descrição externa de sua origem. Excluir a pergunta pelo autor seria, no mínimo, reduzir toda arte a um e mesmo denominador (Scholtz, 1995, p. 115).

A interpretação técnica, no sentido específico do termo, 
situa-se na tensão entre a vontade ou intenção de comunicação do autor e as formas de linguagem de que este dispõe para a sua manifestação. Segundo Schleiermacher, as tradicionais categorias da linguagem, e mesmo suas convenções artísticas dominam e limitam o artista, mas ele, por sua vez, exercitando a imaginação, também pode romper a tradição e criar novas formas. Todo discurso é articulado nos limites da linguagem, mas, em virtude da capacidade de imaginação e de criação, é também um constante deslocar desses pelo autor, deixando neles sua marca, seu estilo, objeto da interpretação técnica.

\section{Comparação e divinação}

Também estes dois conceitos - comparação e divinação podem enriquecer a discussão sobre a imaginação na hermenêutica de Schleiermacher. Seria dispensável falar da importância da comparação. Constantemente lança-se mão dela. É em virtude da comparação que se distingue entre sentido novo e velho, amplo e restrito, convencional e revolucionário. Ninguém questiona esse procedimento. $\mathrm{O}$ que, entretanto, precisa de mais esclarecimento é a divinação, que já recebeu as mais diversas interpretações. Trata-se simplesmente de um procedimento da imaginação, a qual ninguém pode dispensar. Não se fala de uma imaginação gratuita, mas de um atinar a partir de dados disponíveis. Assim como a concepção da forma da obra, ou seja, a estrutura do todo, só é possível pela fantasia, a divinação, segundo Schleiermacher, é o esforço de refazer o projeto criador e imaginário do autor. É a tentativa de refazer a singularidade estilística do autor. Isso, com certeza, não vem em prejuízo de nenhum procedimento científico, mas, ao contrário, o complementa e, inclusive, faz parte dele (Scholtz, 1995, p. 116). É um plus, que se soma aos procedimentos mais técnicos e padronizados da leitura de um texto. 
Esses dois métodos de procedimento, mais uma vez, correspondem à dupla concepção do discurso, bem como de sua compreensão: enquanto expressão de uma língua e enquanto fato naquele pensa. Num é o sistema, ou a totalidade da linguagem que entra em consideração. Torna-se referência para a comparação ou a avaliação do texto em questão. Enquanto isso, no segundo caso, onde se considera a totalidade e a singularidade do autor, reconhece-se que não há um caminho lógico e seguro, que nos possa conduzir à compreensão do discurso. Sempre permanecerá uma distância. Para superar ou diminuir essa distância, entra a divinação, um "salto" da imaginação, à semelhança da projeção e da imaginação originárias do autor.

\section{O círculo hermenêutico}

Com o método da comparação também chegamos à questão do círculo hermenêutico. Heidegger, em sua analítica do Dasein, mostra como o círculo é da própria estrutura da compreensão e da interpretação (1989, p. 33). Em Heidegger, a pergunta pelo ser é possível, porque já sempre há uma précompreensão do ser, uma compreensão vaga e implícita. A pergunta, entretanto, surge porque se quer compreender melhor e explicitar o que apenas está implícito. $\mathrm{Na}$ medida em que houver essa explicitação, haverá condições para reformular a pergunta, e assim sucessivamente. Já o projeto hermenêutico de Schleiermacher apontava, de alguma forma, para o sentido estrutural desse círculo de interpretação, círculo hermenêutico, "demonstrando a complementaridade fundamental entre os aspectos particular e universal" ou o todo e a parte de uma interpretação.

Qualquer uma das duas perspectivas hermenêuticas, argumenta 
ele, degenera em abstração quando não complementada pela outra: o particular só pode ser compreendido a partir do todo (universal) e este somente a partir do particular, porque um existe como síntese com o outro (Ruedell, 2000, p. 185). ${ }^{3}$

A origem desse círculo está na "dependência mútua entre o aspecto gramatical e o psicológico, objetivo e subjetivo". É precisamente aí, na conjugação dos dois aspectos, que se mostra particularmente a capacidade de imaginação do leitor ou intérprete. Está também aí a "universalidade e se desenha todo o quadro do método interpretativo. Nenhum procedimento hermenêutico é possível sem essa complementaridade" (Ruedell, 2000, p. 185-186).

\section{A interpretação como divinação}

Ao falar em imaginação na hermenêutica de Schleiermacher, é importante que ainda se faça uma abordagem específica do termo e conceito divinação $o^{4}$ (Divination), já várias vezes referido. Nesse conceito concentra-se o que há de mais peculiar na teoria hermenêutica de Schleiermacher, e o que também já recebeu as mais desencontradas interpretações. Gadamer, por exemplo, identifica-o sem mais com o termo "sentimento", no sentido de uma misteriosa compreensão interior, ${ }^{5}$ fundada sobre uma identidade originária ou congenial entre autor e intérprete. Com essa explicação ele, em verdade, esvazia o teorema da divinação, de modo a sustentar a tese de que Schleiermacher não levava tão a sério sua "relativização especulativa" da compreensão. "A barreira - diz ele - que permanece para a razão e o ato da compreensão, não é em todos os sentidos intransponível. Ela deve ser superada pelo sentimento [compreensão interior], portanto, por uma compreensão direta misteriosa e congenial" (Gadamer, 1990, p. 194). ${ }^{6}$ Nessa perspectiva, devido à identificação entre autor e 
leitor, a divinação anularia a distância entre eles, situando-se acima ou fora da história. É uma concepção que desconsidera o vínculo necessário entre linguagem e pensamento e, por conseguinte, também entende a própria "reconstrução objetiva da intenção de outrem" como um evento não-lingüístico (Frank, 1985 , p. 315). Não é isso que está contido na divinação de Schleiermacher.

O termo esclarece-se adequadamente em seu contexto de origem, na hermenêutica do estilo, cuja compreensão necessita da divinação. Esta designa "aquela atitude de consciência do intérprete que corresponde à da produtividade estilística do autor". Como o estilo é sempre singular e único, também o autor, enquanto sujeito de um estilo, não tem padrão ou regra pelos quais se possa guiar com segurança. Ele pensa e abre seu próprio caminho, da mesma forma como projeta e imagina o todo da obra. Graças à faculdade da imaginação, ele consegue elaborar projetos, pensar e projetar sua pesquisa, programar a publicação de um livro, enfim, imaginar previamente toda a sua construção, marcada pela peculiaridade de seu pensamento e de seu estilo. O que se dá por primeiro, segundo Schleiermacher, é a idéia da obra. É sua concepção e a projeção pelo autor que permitem sua execução. (Schleiermacher, 2005, p. 203). Portanto, a imaginação está na concepção da obra e na singularidade estilística de sua composição.

O desafio da divinação é compreender esse aspecto singular e único, designado como estilo de uma obra. Por isso, da mesma forma como na construção estilística de uma obra, também aqui não há padrão ou regra que pudesse garantir uma interpretação correta. $\mathrm{O}$ singular evade-se da padronização. Não há um caminho lógico que conduz ao outro, diferente ou único. Sempre permanece uma distância, e a divinação significa um salto da faculdade de imaginação pelo qual se procura vencer essa distância.

É preciso, porém, prestar atenção à expressão “procura 
vencer". Schleiermacher não tem a ilusão de que seja possível anular totalmente essa distância. Como sempre permanece uma diferença entre os indivíduos, da mesma forma nunca se chegará a uma identificação perfeita entre a peculiaridade estilística de um texto e sua compreensão pelo leitor ou intérprete. É uma compreensão por aproximação, que ainda sempre pode ser aprimorada. Mas, mesmo que esse ideal da compreensão perfeita seja, em princípio, inatingível, constitui-se, contudo, num fator de orientação e de motivação para buscar o aprimoramento da compreensão. $\mathrm{Na}$ perspectiva da hermenêutica, ela nunca se dá de uma vez por todas, mas é um processo ou uma busca interminável, viabilizada pelo recurso da linguagem e pela faculdade da imaginação.

Tanto a criação da obra quanto sua compreensão e interpretação são produzidas pela imaginação, da qual ninguém pode prescindir. Não se trata, porém, de uma imaginação gratuita ou adivinhação aleatória, e sim de um atinar a partir dos dados disponíveis. Não há imaginação a partir de nada, como também não existe um estilo sem a linguagem. Assim como a concepção da forma da obra, a estrutura do todo só é possível pela fantasia, a divinação, segundo Schleiermacher, é o esforço de refazer o projeto criador e imaginário do autor. É a tentativa de refazer a singularidade estilística de uma obra (interpretação técnica) e de seu autor (interpretação psicológica).

\section{A arte de compreender e interpretar}

A concepção da hermenêutica como arte de compreender e de interpretar (Schleiermacher, 1990, p. 71) refere-se mais à destreza ou à habilidade do intérprete do que a um seguimento rigoroso de regras metódicas de interpretação. Destaca-se aí a atitude e o procedimento hermenêutico do sujeito, que, com suficiente "jogo de cintura" ou flexibilidade, é capaz de incluir 
em sua interpretação as circunstâncias particulares que the dizem respeito. "A verdadeira tarefa da hermenêutica - afirma Schleiermacher - deve ser entendida como obra de arte" (Schleiermacher, 1995, p. 99), mas não como se a sua execução fosse terminar na constituição de uma obra de arte, e sim no sentido de que a atividade traz apenas em si "o caráter de arte, porque com as regras não está dada também a aplicação, isto é, não pode ser mecanizada" (Schleiermacher, 1995, p. 99). As regras da linguagem não se aplicam por si, da mesma forma como a própria linguagem não funciona ou não existe sem a atuação das respectivas comunidades lingüísticas, que a mantêm.

A interpretação é arte porque é um constante ir e vir entre o universal e o particular. Cada discurso é, em verdade, "a construção de um determinado finito", que "existe a partir de um indeterminado infinito", que é a linguagem. Esta é infinita porque "cada elemento pode ser determinado de uma maneira particular pelos demais". E o mesmo também se pode dizer do aspecto psicológico, "pois cada intuição de alguém particular é infinita". No mais, as influências "de fora sobre o ser humano, em relação ao infinitamente distante, é também algo que diminui gradativamente" (Schleiermacher, 1990, p. 99). É, portanto, aí, na articulação entre o universal e o particular, o finito e o infinito, que entra em cena a faculdade da imaginação do intérprete. Para a construção e a interpretação de uma realidade tão complexa, não há regra possível que pudesse trazer em si a certeza de sua aplicação.

\section{Considerações finais}

Para estabelecer um ponto final, cabe lembrar mais uma vez, a dupla concepção da linguagem e da interpretação, que se encontra na hermenêutica de Friedrich Schleiermacher. Numa 
perspectiva, considera-se prioritariamente o caráter sistemático de um discurso, que vem a ser objeto da interpretação gramatical, enquanto que a outra volta-se para o aspecto da gênese do discurso (autor e estilo), objeto da interpretação psicológica e/ou técnica. Ao tratar a questão da imaginação, dei um destaque especial ao lado subjetivo, chamando atenção para a função criadora e inovadora do autor e do leitor ou intérprete de uma obra. Isso, porém, sem descuidar de frisar que nada se cria ou imagina sem a linguagem. Se é verdade que o indivíduo é capaz de inovar na linguagem, é novamente esta que lhe permite introduzir essa inovação. É um certo paradoxo, que talvez se elucida mais com uma comparação. À semelhança da aranha, que se segura na teia que constrói, o homem que inova na linguagem somente avança com ela, e não consegue pisar fora dela, da mesma forma como a aranha também não cai de sua teia.

\section{Notas}

1 "Beide stehen einander völlig gleich, und mit Unrecht würde man die grammatische Interpretation die niedere und die psychologische die höhere nennen"(Schleiermacher, 1990, p. 79).

2 A citação completa do cânon é a seguinte: "Alles, was noch einer näheren Bestimmung bedarf in einer gegebenen Rede, darf nur aus dem Verfasser und seinem ursprünglichen Publikum gemeinsamen Sprachgebiet bestimmt werden" (Schleiermacher, 1974, p. 86 e 1990, p. 101).

3 No original alemão: "...dass wie freilich das Ganze aus dem Einzelnen verstanden wird, so doch das Einzelne nur aus dem Ganzen verstanden werden könne, ist von solchem Umfang für diese Kunst und so unbestreitbar, dass schon die ersten Operationen nicht ohne Anwendung desselben zu Stande gebracht werden können,..." (Schleiermacher, 1974, p. 141-142).

4 Opção de tradução, porque o termo "adivinhação" já estaria muito marcado por uma adivinhação aleatória.

5 No alemão "Einfühlung", ou também "Gefühl". Em Gadamer, 1990, p. 193, pode-se ler: "...dass auch der letzte Grund alles Verstehens immer ein divinatorischer Akt der Kongenialität sein muss, dessen Möglichkeit auf einer vorgängigen Verbundenheit allen Individualitäten beruht", e em 
Gadamer, 1990, p. 194: "...das Gefühl, also ein unmittelbares sympathetisches und kongeniales Verstehen..."

6 No original alemão: "Die Schranke, die der Vernunft und dem Begreifen hier bleibt, ist nicht in jedem Sinne unübersteigbar. Sie soll durch das Gefühl, also ein unmittelbares sympathetisches und kongeniales Verstehen, überschritten warden" (Gadamer, 1990, p. 194)."

\section{Referências}

FRANK, Manfred. Das individuelle Allgemeine; Textstrukturierung und -interpretation nach Schleiermacher. Frankfurt a. Main: Suhrkamp, 1985.

GADAMER, H.-G. Gesammelte Werke-1; Hermeneutik-I: Wahrheit und Methode-1. Grundzüge einer philosophischen Hermeneutik. 6. Aufl., Tübingen: Mohr, 1990.

HEIDEGGER, M. Ser e Tempo - I. 3.ed. Tradução de Márcia de Sá Cavalcante. Petrópolis: Vozes, 1989.

SCHLEIERMACHER, Friedrich Daniel Ernst. Hermeneutik. Nach den Nachschriften neu herausgegeben und eingeleitet von Heinz Kimmerle. 2. verb. u. erweiterte Aufl. Heidelberg: Carl Winter Universitätsverlag, 1974.

. Hermeneutik und Kritik; mit einem Anhang sprachphilosophischer Texte Schleiermachers. Hrsg. und eingeleitet von Manfred Frank, 4.Aufl. Frankfurt a. Main: Suhrkamp, 1990.

. Hermenêutica e Crítica; com um anexo de textos de Schleiermacher sobre filosofia da linguagem - I . Tradução de Aloísio Ruedell e Revisão de Paulo R. Schneider. Ijuí/RS: UNIJUÍ, 2005.

. Das Leben Jesu (1832). Aus Schleiermchers handschriftlichem Nachlasse und Nachschriften seiner Zuhörer, hrsg. von K. A. Rutenik. Berlin, 1864.

SCHOLTZ, Gunter. Ethik und Hermeneutik; Schleiermachers Grundlegung der Geisteswissenschaften. Frankfurt a. Main: Suhrkamp, 1995. 